\title{
How to set-up a long-distance mentoring program: a framework and case description of mentorship in HIV clinical trials
}

This article was published in the following Dove Press journal:

Journal of Multidisciplinary Healthcare

7 January 2013

Number of times this article has been viewed

\author{
Lawrence Mbuagbaw ${ }^{1,2}$ \\ Lehana Thabane $e^{2,3}$ \\ 'Centre for the Development of Best \\ Practices in Health (CDBPH), Yaoundé \\ Central Hospital, Henri Dunant \\ Avenue, Messa, Yaoundé, Cameroon; \\ ${ }^{2}$ Department of Clinical Epidemiology \\ and Biostatistics, McMaster University, \\ Hamilton, ON, Canada; ${ }^{3}$ Biostatistics \\ Unit, Father Sean O'Sullivan Research \\ Centre, St Joseph's Healthcare, \\ Hamilton, ON, Canada
}

\begin{abstract}
Mentoring plays an important role in learning and career development. Mentored researchers are more productive and more likely to publish their work. However, mentorship programs are not universally used in most settings or disciplines. Furthermore, successful and mutually beneficial mentoring relationships are not always easy to arrange. Long-distance mentoring relationships are even more difficult to handle and may break down for a wide variety of reasons. Drawing from our experiences with the first Canadian Institutes of Health Research - Canadian HIV Trials Network international postdoctoral fellowship program, we describe the roles of the context, the key mentor and the mentee attributes; goals and expectations; environments, local support, a communication plan, funding, face-to-face contact, multidisciplinary collaboration, co-mentoring, and evaluation as they apply to the successful implementation of a long-distance mentoring program.
\end{abstract}

Keywords: long distance, mentoring, framework, Canada, Cameroon

\section{Introduction}

Mentoring is a process that engages an often elder and more experienced mentor and a younger mentee in a complex dynamic relationship of knowledge transfer based on predefined goals. However, the scope of mentoring is considerably large and various definitions have been used that illustrate these differences. ${ }^{1,2}$ Mentored graduate students are more likely to publish their research and to be generally more productive. ${ }^{3-5}$ Mentoring is an important element of early career success..$^{1,3,6}$ Mentors bring additional skills that can't be learned in a classroom, which can improve the mentees' chances for a successful career. Some of these skills include time management, organization of work, scientific writing, financial management, and the prevention and resolution of conflicts. ${ }^{3}$ Mentoring is considered a crucial part of academic medicine and essential to successful research. ${ }^{7,8}$ Mentors and their respective mentees report favorably on the benefits of mentoring, the quality of a mentoring relationship, and generally positive outcomes in academia. ${ }^{6,9}$

Given the above, a mentor in health research can be defined as a senior, influential, well-connected colleague who willingly shares experiences, resources, knowledge, and career development skills with a mentee. Personal advice may also be offered depending on the relationship dynamics of the mentor-mentee team.

Mentoring relationships may develop spontaneously or informally and grow over time, or mentoring duties may be assigned to a mentor. ${ }^{10}$ A supervisor-student relationship may evolve into a mentor-mentee relationship and a mentor could also be an administrative leader within the same institution. Some authors suggest that ethnic minorities
Correspondence: Lawrence Mbuagbaw Centre for the Development of Best Practices in Health (CDBPH), Yaoundé Central Hospital, Avenue Henri Dunant, Messa, PO Box 87, Yaoundé, Cameroon $\mathrm{Tel}+\mathrm{I} 9055259140$ ext 22430

Email mbuagblc@mcmaster.ca 
are less likely to have a mentor and that women are less likely to be satisfied with the interpersonal relationships they have with their mentors. ${ }^{3}$ It is unclear how often formal mentorship and mentor-training programs are used in academic institutions. ${ }^{11}$ Conflicting values and long-term goals may lead to counter-productive mentor-mentee relationships. ${ }^{12-14}$

Achieving the goals of a mentor-mentee relationship may be even more daunting when the two parties are in geographically distinct locations. This may occur when, in order to find a good mentor-mentee match, the pool of candidates is extended to the international community. ${ }^{3}$ In long-distance mentoring relationships, there is little or no physical contact between the mentor and the mentee. The mentor is not "down the hall", so the mentee must be able to exploit other resources, and make use of each communication opportunity. Such a relationship requires more time and effort to grow. Both mentor and mentee must be satisfied with the lack of face-to-face communication. Advances in communication technology have made such relationships possible through conference calls, emails, and faxes.

A key feature of long-distance mentoring is that it offers the possibility of rapid, less costly, knowledge transfer and capacity-strengthening without the disruption of service provision, which occurs with traditional forms of training that require service providers or researchers to be displaced from their place of work for extended periods of time. ${ }^{1}$ Longdistance mentoring also exposes the mentor and mentee to the realities of different working environments.

In order to strengthen and sustain research efforts to curb the human immunodeficiency virus (HIV) epidemic, the next generation of HIV research scientists needs to be mentored. They need to know and avoid the limitations of working in isolation and to understand the benefits of multidisciplinary teamwork and networking. ${ }^{15}$ Mentoring for clinical scientists in low-resource settings is insufficient, ${ }^{16,17}$ and many African researchers have not benefitted from the widely recognized benefits of mentoring. ${ }^{1}$ Thus said, in the light of the broad scope of the mentoring process and the potential challenges of long-distance mentoring, it is necessary to establish a concrete experience-based framework, which can be replicated and compared to theory-based frameworks.

In this paper, we propose a framework for setting up a long-distance mentorship program for researchers, and describe the example of the first Canadian Institutes of Health Research (CIHR) Canadian HIV Trials Network (CTN) international fellowship program such that it can be used by mentors and mentees in other settings.

\section{A proposed framework}

This framework was developed by reviewing the literature on long-distance mentoring and critically appraising the CIHRCTN international postdoctoral fellowship. Both mentor and mentee identified the factors that enhanced the relationship. We classify the components of a long-distance mentorship program as critical, important, or supportive. These classifications are not meant to be fixed, but rather dynamic and the components can be placed at different levels of importance based on the context of the relationship. This framework is summarized in Table 1.

\section{The context}

The context of the relationship should be defined in terms of who is participating and why. It could be between a medical student and a professor as a long-term relationship for guidance in the medical profession or as part of a fellowship with specific knowledge- and skill-transfer objectives. It could also be set up to enable the completion of a specific research endeavor such as a systematic review. ${ }^{18}$

Table I A framework for setting up a long-distance mentoring program

\begin{tabular}{lll}
\hline Level of importance & Components & Description \\
\hline Critical & Context & The context defines the purpose of the relationship, funding available, and duration \\
& Mentor & An experienced, knowledgeable, and committed mentor \\
& Gentee & A motivated and productive mentee \\
& Environments & Specific goals and expectations established mutually \\
Communication plan & An environment creating the need for long-distance mentoring \\
Important & A pre-established communication plan specifying the frequency and type of communication & Sufficient funds to ensure communication and achievement of goals \\
& Face-to face contact & At least one face-to-face meeting is desirable \\
Supportive & Other senior researchers to broaden mentee's horizons and foster interdisciplinary collaboration \\
& Co-mentoring & Reduces the burden of mentoring and increases sources of knowledge \\
& Local support & Essential to keep mentee comfortable with the relationship \\
& Evaluation & The success and impact of the mentoring should be evaluated using measurable outcomes \\
\hline
\end{tabular}


It is important to examine how mentee and mentor are brought together, what characteristics they have in common, why mentoring is necessary, and how these can be used to build the relationship. The context therefore defines the pool from which mentors and mentees are drawn, the goals of the relationship, and the resources that may be useful in achieving these goals.

\section{The mentor}

A systematic review identified seniority, being knowledgeable, experienced, and well respected in their fields as desirable traits in a mentor. ${ }^{19}$ The characteristics of the mentor are a critical aspect of a mentoring relationship. For a long-distance mentoring relationship, the mentor must be comfortable with limited face time and other forms of communication. The mentor must be willing to commit to a relationship with a junior, inexperienced scientist. Additional motivation for mentoring may include opportunities for interaction, improved job performance and recognition, exposure to new ideas, and self-fulfillment since mentoring can be a rewarding experience. ${ }^{20}$

\section{The mentee}

A productive mentee with zeal to learn is critical to a longdistance mentoring relationship. The mentee should be able to demonstrate progress between meetings or phone calls and be comfortable working with limited supervision.

\section{Goals and expectations for a mentor-mentee relationship}

A potentially successful mentorship program requires specific goals that guide the knowledge-transfer techniques used and define how progress and success can be monitored and evaluated. Mutually clear expectations prevent frustrations and lack of satisfaction with the relationship. The goals can be short term such as completion of a course or research project; or long term, throughout the mentee's career.

\section{The environments}

The environments surrounding the mentor-mentee relationship are important. Firstly, the environments create the need for the relationship in the first place. For a long-distance relationship, the mentee will most likely be in a research environment with limited capacity and limited potential for local mentorship. There may also be a need for a geographical transfer of skills and knowledge. This environment fosters the relationship by creating a quasidependence of the mentee on the mentor.

\section{Communication plan}

It is equally important to establish a communication plan for the mentoring relationship. Specific dates for progress reports must be set. Mutually convenient times for phone calls should be determined so that communication is not inconvenient. This communication can serve the following purposes: knowledge transfer; reporting and updating; feedback and evaluation.

\section{Funding}

The kind of funding required to ensure a fruitful long-distance mentorship relationship will vary greatly depending on the context. Funding must also be sufficient to keep the mentee from seeking other sources of finances that may distract him from research. Within the scope of a fellowship or a formal training program, resources must be set aside for communication, transportation, and achieving the goals of the fellowship. The mentor and mentee may also have some personal resources, depending on where they work and their levels of income. Such personal resources are important to maintain communication and also show commitment to the relationship. Funding is also necessary for face-to-face contact. On the other hand, interpersonal relationships that evolve into mentoring relationships may not necessarily require any funding.

\section{Face-to-face contact}

Putting a face to the voice is an important way of strengthening long-distance mentorship relationships. ${ }^{21}$ We propose that the mentor and mentee meet physically at least once. This of course would depend on the resources available for this kind of meeting and may vary depending on the geographical distance between the parties.

\section{Working with a multidisciplinary team of researchers}

One important component of mentorship is that the mentor uses his resources to the benefit of the mentee. This should involve sharing collaborative networks and introducing the mentee to researchers in other fields. This broadens the mentees' horizons and may facilitate the achievement of goals. It also introduces the mentee to interdisciplinary collaboration, which is vital for research. ${ }^{15}$

\section{Extending the network through co-mentoring and mobilizing additional resources}

co-mentoring may be more rewarding and less demanding than sole mentoring. ${ }^{21}$ The mentor may know other senior 
researchers who are knowledgeable in other fields of interest that may help the mentee. In this way the mentee may receive support from other institutions. However, there is also a potential for conflicting ideologies to stifle the learning process.

\section{Local support}

Local support is valuable to the development of a viable longdistance mentorship. Such a relationship requires that the mentee be capable of working independently. This becomes challenging if the mentee has no local support in terms of infrastructure or colleagues and supervisors who understand his commitment to an external mentoring relationship.

\section{Evaluation of the relationship}

A long-distance mentoring relationship is a complex multifaceted endeavor. Certain key products can help to determine if a long-distance mentoring relationship was fruitful, but should be distinguished from events that would have occurred in the absence of mentoring.

Goals and expectations set a priori should be re-evaluated. The relationship should be examined critically to identify its strengths and weaknesses.

\section{Research productivity}

The mentor and mentee should document all oral and poster presentations and journal articles that arise from their collaborative efforts.

\section{Career growth}

Career advancements of the mentee such as completion of degree programs, obtaining tenure, securing additional research funding or academic positions that clearly involved skills obtained through mentoring or the support of the mentor should be documented.

\section{Mentee evolving into mentor}

If it is relevant to the purpose of the mentor-mentee relationship, the mentee should evolve into a mentor. This is a particularly desirable outcome as it ensures the continuity of the mentoring process.

\section{Applying this framework to the CIHR-CTN's first international postdoctoral fellowship in HIV clinical trials Context}

The CTN is an initiative from a coalition of researchers dedicated to advancing HIV care through a decentralized network of geographically diverse Canadian clinics and hospitals (see http://www.hivnet.ubc.ca). They collaborate with international and national stakeholders in HIV control and recently aligned their activities with the CIHR.

The CTN offers one international fellowship to train a scientist who is dedicated to HIV treatment or prevention research in a resource-limited country. The holder must have completed an $\mathrm{MD}$ or a $\mathrm{PhD}$, and identified a suitable Canadian-based mentor and local host institution that will provide support, research facilities, and time to conduct the fellowship. The goal of this fellowship is to improve clinical HIV research capacity in low-resource settings. The first international postdoctoral fellowship was launched in 2010. The fellowship was awarded to a Cameroonian researcher with a primary mentor in Canada.

The mentor-mentee contact was initiated by a mutual acquaintance, who shared the curriculum vitae of the mentee with the future mentor.

\section{The mentor}

The mentor (LT) is currently a Professor of Biostatistics in the Department of Clinical Epidemiology and Biostatistics, McMaster University and Director of Biostatistics at the Centre for Evaluation of Medicines (CEM), Father Sean O'Sullivan Research Centre at St Joseph's Healthcare. He has supervised and mentored many MSc and PhD students. He has coauthored several papers and presentations at national and international meetings with all his students and mentees as lead authors or coauthors. His mentoring approach empowers his students and mentees to feel motivated to tackle their research tasks with enthusiasm and confidence, which are two of the key attributes necessary for successful transition to becoming independent investigators. He has also written about some of the mentoring techniques that he uses to support his students and mentees to gain important career skills. ${ }^{22} \mathrm{He}$ is a CIHR Clinical Trials Mentor and a mentor for the Isibalo Young Statisticians Program - a mentorship program for young statisticians aimed at building capacity for the development of statistics in Africa (see http://www. statssa.gov.za/ycs/about_isibalo.htm). These attributes made him the ideal choice for a challenging first-time long-distance mentorship program.

\section{The mentee}

LM has been interested in research from the early stages of his career, and had already published case reports and analytical studies in peer-reviewed journals. He is a Medical Doctor with a Master's Degree in Public Health. He is also well 
versed with communication technologies and easily accessible by email and phone. His interest in HIV/AIDS research and ability to work independently were important for a longdistance mentoring relationship in HIV clinical trials.

\section{Goals and expectations}

The overarching objective was to improve the mentee's skills as a clinical researcher for HIV. Specific activities that were outlined in the work plan included developing a protocol for a clinical trial, attending two skill-building CTN semiannual meetings, developing skills as a scientific reviewer, conducting a systematic review, and training in knowledge translation.

LM's expectations were discussed from the onset using the fellowship as a stepping-stone towards a PhD in Health Research Methodology.

\section{The environments}

Cameroon is a low-resource middle-income country with significant limitations in health-research capacity mostly due to the meager amounts allocated to health research and poor remuneration of health researchers. This has led to a stall in the transfer of research capacity and demotivation of senior and young researchers alike. ${ }^{23}$ The CIHR-CTN's goal of transferring capacity was aligned with the mentee's personal goals and created a favorable environment for using a long-distance mentoring technique for the fellowship.

\section{Local support}

The Center for the Development of Best Practices in Health (CDBPH) is a research unit created in June 2008 in Cameroon, in order to promote evidence-based health care decision-making with support from a Global Health Leadership Award from the International Development Research Centre (IDRC). The CDBPH (see http://www.cdbph.org) provided research space and support during the tenure of the postdoctoral fellowship. It also offered opportunities for knowledge translation and research synthesis. LM facilitated workshops on evidence-based medicine and benefitted from the resources of the CDBPH to complete a systematic review. ${ }^{24,25}$ Such opportunities would have been logistically challenging were they to come from a geographically distant mentor.

\section{Communication plan}

Monthly email updates, quarterly teleconferences, and regular emails were used for communication. Communication was further enhanced during two face-to-face visits.
The monthly emails kept the mentor informed of progress. The teleconferences brought the co-mentors together to discuss ways in which resources could be shared to enhance the mentoring relationship and achievement of goals.

\section{Funding}

The CTN International postdoctoral fellowship provided 35,000 CAD for the mentee, which covered salary and travel. For a mentorship program to work, sufficient funding is necessary to cover face-to-face meetings, Internet, and phone call costs. Apart from the funding for the fellowship, the mentor also had additional resources, which permitted him to purchase some useful textbooks for the mentee that were relevant to clinical trials. The mentee on his part employed considerable resources in completing the application and setting things in motion before the fellowship funds were available.

\section{Face-to-face contact}

During the two CTN semiannual meetings, the mentormentee relationship was consolidated by lengthy discussions on issues raised by both parties. They evaluated the progress of the relationship in the light of a priori goals and set objectives for the near future.

\section{Working with a multidisciplinary team of researchers}

The host institution, the CDBPH, has a team of multidisciplinary researchers, which includes anthropologists, sociologists, public health specialists, health economists, and clinicians. During LM's visits to Canada, he met with other researchers from various domains. Additional networks created by the mentors enabled the mentee to interact with many other researchers. These interactions inspired many of the mentee's subsequent publications.

\section{Extending the network through co-mentoring and mobilizing additional resources}

During his visits to Canada, LM was able to meet other very experienced HIV researchers who offered guidance for his project. He was exposed to more experts and opinions. This approach is more successful when a primary mentor is identified and the secondary mentors have complementary expertise, as was the case here. Some amount of mentorship was provided from many other scientists within a network created by the primary mentor, the host institution, and other institutions, as was the case with the South African 
Cochrane Centre (SACC) and the Global Health Clinical Trials Platform.

The SACC was established to develop expertise in research synthesis and systematic reviews on the African continent. They improve capacity building for HIV systematic reviews through their Cochrane HIV mentorship program. After linking a mentee with an experienced mentor they provide assistance with protocol development, exhaustive searches, evaluation and summarizing the evidence. The SACC (see http://www.mrc.ac.za/cochrane/) provided support towards the completion of a systematic review and co-funded knowledge translation opportunities. The SACC played a crucial role in helping the mentee to complete his systematic review and train other novice authors.

The Global Health Clinical Trials Research Platform is an open collaborative program, which promotes and facilitates noncommercial trials in low-resource settings by providing tools, resources, guidance, and training to support trials. They provide an online forum for issues surrounding the organization and conduct of trials in low-resource settings (see http://www.globalhealthtrials.org). This forum was used to discuss with other researchers and share experiences during the fellowship.

\section{Evaluation of the relationship}

The goals and expectations of the mentee were achieved at the end of the 1-year fellowship. LM started his PhD studies in the Health Research Methodology Program at McMaster University in January 2012 (see hrm.mcmaster.ca).

LM and LT jointly prepared and published three peerreviewed manuscripts and two poster presentations. ${ }^{26-30} \mathrm{LM}$ also completed one book chapter. ${ }^{31}$

LM succeeded to secure the Canada-HOPE Scholarship and the Ontario Trillium Scholarship for PhD studies.

After successful completion of his CTN fellowship in June 2011, LM assumed a co-mentoring role (with LT) for another international postdoctoral fellow for 2011-2012 and mentoring role for an author of a Cochrane review in $2011 .^{32}$

\section{Lessons learnt and barriers}

Long-distance mentoring is a viable option for research knowledge transfer that requires a good mentor-mentee match and specific goals. It can benefit from adequate communication, face-to-face meetings, funding, multidisciplinary collaboration, co-mentoring, and local support for the mentee. Mentor-mentee matching should be negotiated based on mutual research interests.
The barriers to a long-distance mentoring relationship are mostly related to communication difficulties and limited face-to-face meetings.

Even though this framework was developed for long-distance mentoring relationships, most of the components may apply to mentor-mentee teams within the same institution. However, in such cases a detailed communication plan may not be very important if the mentor is "across the hall".

\section{Conclusion}

We encourage the development of more long-distance mentorships programs to enhance knowledge transfer and career development initiatives in health research. We also recommend the establishment of formal mentorship relationships within low-resource countries, for various medical disciplines so that the already available skills can be transmitted effectively, and the benefits of mentoring relationships can be enjoyed.

Mentorship programs should exist within a defined framework and use measurable outcomes to evaluate their effectiveness including achievement of goals, scholarly products like publications, career growth and evolution of the mentee into a mentor.

\section{Contributions}

LM conceived of the paper. LT helped to draft and review several versions of the manuscript. All authors read and approved the final manuscript.

\section{Acknowledgments}

This paper is supported in part by the Canadian Institutes of Health Research (CIHR) HIV Clinical Trials Network (CTN) in the form of an international postdoctoral research fellowship awarded to the first author. Professor Thabane is a clinical trials mentor for CIHR under the Randomized Controlled Trials (RCT) Mentorship Program. This paper is also partially supported by the CANNeCTIN program.

\section{Disclosure}

The authors declare they have no competing interests.

\section{References}

1. Matovu JK, Wanyenze RK, Mawemuko S, et al. Building capacity for HIV/AIDS program leadership and management in Uganda through mentored Fellowships. Glob Health Action. 2011;4:5815.

2. Healy NA, Cantillon P, Malone C, Kerin MJ. Role models and mentors in surgery. Am J Surg. 2012;204(2):256-261.

3. Long-distance relationships. Nat Neurosci. 2007;10(10):1223.

4. Steiner JF, Lanphear BP, Curtis P, Vu KO. Indicators of early research productivity among primary care fellows. J Gen Intern Med. 2002;17(11): $845-851$ 
5. Sambunjak D, Straus SE, Marusic A. Mentoring in academic medicine: a systematic review. JAMA. 2006;296(9):1103-1115.

6. Eby LT, Allen TD, Evans SC, Ng T, Dubois D. Does mentoring matter? A multidisciplinary meta-analysis comparing mentored and non-mentored individuals. J Vocat Behav. 2008;72(2):254-267.

7. International Working Party to Promote and Revitalize Academic Medicine. ICRAM (the International Campaign to Revitalise Academic Medicine): agenda setting. BMJ. 2004;329(7469):787-789.

8. Kupfer DJ, Hyman SE, Schatzberg AF, Pincus HA, Reynolds CF 3rd. Recruiting and retaining future generations of physician scientists in mental health. Arch Gen Psychiatry. 2002;59(7):657-660.

9. Longo DR, Katerndahl DA, Turban DB, et al. The research mentoring relationship in family medicine: findings from the grant generating project. Fam Med. 2011;43(4):240-247.

10. Jackson VA, Palepu A, Szalacha L, Caswell C, Carr PL, Inui T. "Having the right chemistry": a qualitative study of mentoring in academic medicine. Acad Med. 2003;78(3):328-334.

11. Feldman MD, Huang L, Guglielmo BJ, et al. Training the next generation of research mentors: the University of California, San Francisco, Clinical and Translational Science Institute Mentor Development Program. Clin Transl Sci. 2009;2(3):216-221.

12. Katerndahl DA, Longo DR, Griswold K. Issues important to the research mentoring relationship. Fam Med. 2011;43(3):193-197.

13. Barondess JA. On mentoring. J R Soc Med. 1997;90(6):347-349.

14. Anderson PC. Mentoring. Acad Med. 1999;74(1):4-5.

15. Kahn JS, Greenblatt RM. Mentoring early-career scientists for HIV research careers. Am J Public Health. 2009;99 Suppl 1:S37-S42.

16. Griffiths M, Miller H. E-mentoring: does it have a place in medicine? Postgrad Med J. 2005;81(956):389-390.

17. Brathwaite D. Mentoring students: internationally. $A B N F J .2002 ; 13(2)$ : $31-33$.

18. de Kock A, Siegfried N, Oliver J, Kennedy G, Hovarth T. How well are we really doing? The HIV/AIDS Mentoring Program five years on. Cochrane Colloquium Abstracts Journal. 2006:O04

19. Sambunjak D, Straus SE, Marusic A. A systematic review of qualitative research on the meaning and characteristics of mentoring in academic medicine. J Gen Intern Med. 2010;25(1):72-78.

20. Allen TD, Poteet ML, Burroughs SM. The mentor's perspective: A qualitative inquiry and future research agenda. JVoc Behav. 1997;51 70-89.

21. Luckhaupt SE, Chin MH, Mangione CM, et al. Mentorship in academic general internal medicine. Results of a survey of mentors. J Gen Intern Med. 2005;20(11):1014-1018.
22. Thabane L, Thabane M, Goldsmith CH. Mentoring young statisticians: facilitating the acquisition of important survival skills. Afr Stat Journ. 2006;2:31-42.

23. Takougang I, Ongolo-Zogo P, Socpa A. Incentives and disincentives for young health researchers in Cameroon. 2007. Available from: http://www.healthresearchweb.org/files/Incentives\%20and\%20 Disincentives\%20for\%20Young\%20Health\%20Researchers\%20in\%20 Cameroon.pdf. Accessed on August 10, 2012.

24. Mbuagbaw L, Wiysonge CS, Nsagha DS, Ongolo-Zogo P, Pantoja T. An introduction to systematic reviews and meta-analysis: a workshop report on promoting evidence based medical practice through capacity building in research synthesis. Pan Afr Med J. 2011;8:15.

25. Mbuagbaw LC, Irlam JH, Spaulding A, Rutherford GW, Siegfried N. Efavirenz or nevirapine in three-drug combination therapy with two nucleoside-reverse transcriptase inhibitors for initial treatment of HIV infection in antiretroviral-naive individuals. Cochrane Database Syst Rev. 2010;12:CD004246.

26. Mbuagbaw L, Thabane L, Ongolo-Zogo P, et al. The Cameroon mobile phone SMS (CAMPS) trial: a protocol for a randomized controlled trial of mobile phone text messaging versus usual care for improving adherence to highly active anti-retroviral therapy. Trials. 2011;12:5.

27. Mbuagbaw L, Bonono-Momnougui RC, Thabane L. Considerations in using text messages to improve adherence to highly active antiretroviral therapy: a qualitative study among clients in Yaounde, Cameroon. HIV AIDS (Auckl). 2012;4:45-50.

28. Mbuagbaw L, Thabane L, Ongolo-Zogo P, Lang T. The challenges and opportunities of conducting a clinical trial in a low resource setting: the case of the Cameroon mobile phone SMS (CAMPS) trial, an investigator initiated trial. Trials. 2011;12:145.

29. Mbuagbaw L, Thabane L, Ongolo-Zogo P, Lang T. Organising a clinical trial in a low-resource settings: the case of the Cameroon mobile phone SMS trial (CAMPS), an investigator initiated trial Can J Infect Dis Med Microbiol. 2011;22(Suppl SB):P083.

30. Mbuagbaw LC, Thabane L, Ongolo-Zogo P, Karanja S. Health workers views on the use of text messages to improve adherence to ART: A cross-sectional survey of health workers involved in CAMPS trial. Can J Infect Dis Med Microbiol. 2012;23(Suppl A):77A.

31. Mbuagbaw L, Shurik E. Community Participation in HIV/AIDS Programs. In: Barros E, editor. HIV-infection - Impact, Awareness and Social Implications of living with HIV/AIDS. New York, NY: InTech; 2011.

32. Okwen MP, Mbuagbaw LCE, Reid S, Njei B. Hepatitis B vaccination for reducing morbidity and mortality in persons with HIV infection. Cochrane Database Syst Rev. 2012;5:CD009886.
Journal of Multidisciplinary Healthcare

\section{Publish your work in this journal}

The Journal of Multidisciplinary Healthcare is an international, peerreviewed open-access journal that aims to represent and publish research in healthcare areas delivered by practitioners of different disciplines. This includes studies and reviews conducted by multidisciplinary teams as well as research which evaluates the results or conduct of such teams or

\section{Dovepress}

healthcare processes in general. The journal covers a wide range of areas and welcomes submission from practitioners at all levels, from all over the world. The manuscript management system is completely online and includes a very quick and fair peer-review system. Visit http://www.dovepress.com/testimonials.php to read real quotes from published authors. 